\section{Air Contrast Fluoroscopy as a Diagnostic Aid During Colonoscopy}

It is controversial whether there is a need for a radiography facility where colonoscopy is performed. If the endoscopist relies unduly on fluoroscopic guidance, the procedure may be more difficult and prolonged (1), but selective use of it can facilitate completion of the examination, particularly when recurrent looping of the scope in a mobile left colon occurs $(2,3)$. An additional advantage, which we have not seen described elsewhere, is the potential to obtain high-quality air contrast films, which may aid management, as a result of air insufflation during endoscopy. When it is not possible to teach the caecum, the demonstration of a lesion in this area radiologically is a compelling argument for persevering with colonoscopy or repeating it, rather than opting for a barium enema (Figure 1). Assessment of a stricture in two additional dimensions is also possible, which is particularly helpful if the en-face view at endoscopy is suboptimal (Figure 2).

Although we have not been able to assess the sensitivity of this technique, which is likely to be poor for small lesions, we would recommend its use in the above circumstances if a radiographic facility is available.

W. Dickey, K.G. Porter

Dept. of Medicine, Queen's University of Belfast, Dept. of Gastroenterology, Belfast City Hospital, Northern Ireland, United Kingdom

\section{References}

1. Waye JD. Colonoscopy without fluoroscopy. Gastrointest Endose 1990; 36: $72-3$.

2. Rogers BHG. Colonoscopy with fluoroscopy. Gastrointest Endose 1990; 36: $71-2$.

3. Saunders BP, Macrae FA, Williams CB. What makes colonoscopy difficult? Gut 1993; 34 (Suppl 1): S46.

Corresponding Author

W. Dickey, M. D.

Dept. of Medicine

Institute of Clinical Science

Grosvenor Road

Belfast BT126 B.J

United Kingdom

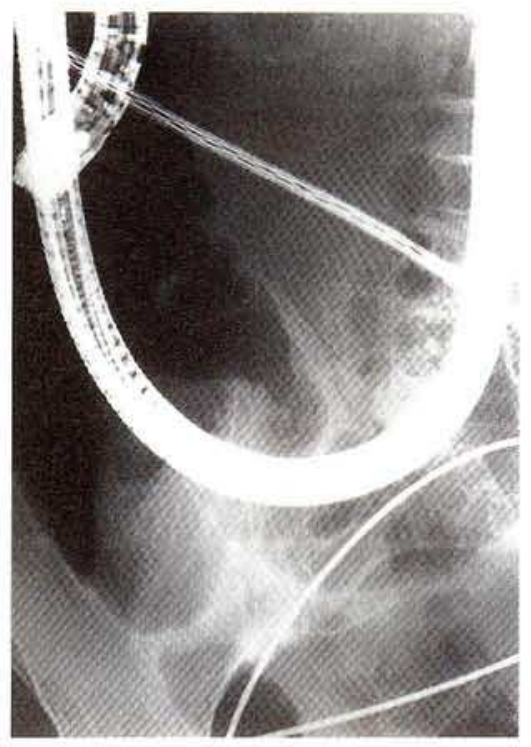

Figure 1: Because of looping, the scope could not be passed to the caecum.

Fluoroscopy showed a caecal mass. Repeat colonoscopy reached the caecum, allowing visual confirmation and biopsy of a large adenocarcinoma.

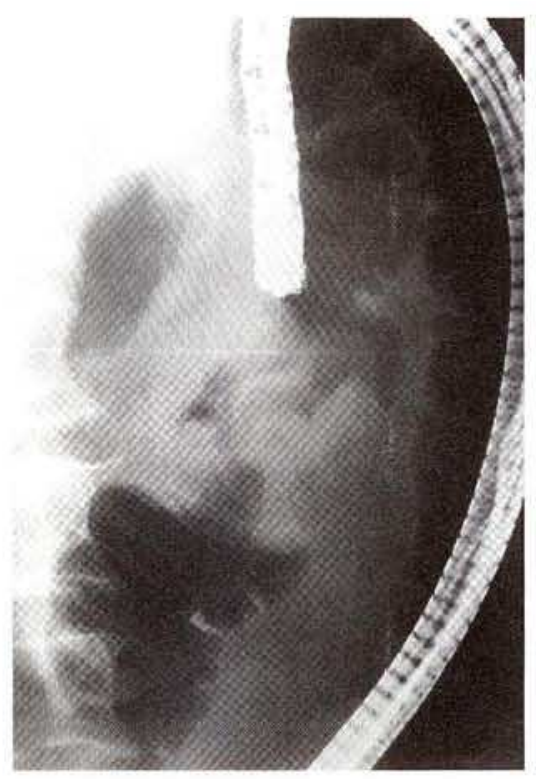

Figure 2: This tight stricture of the transverse colon shows a typical malignant "apple-core" appearance on fluoroscopy. 